\title{
Hemoglobins Likely Function as Peroxidase in Blood Clam Tegillarca granosa Hemocytes
}

\author{
Sufang Wang, ${ }^{1,2}$ Xiaopei Yu, ${ }^{2}$ Zhihua Lin, ${ }^{2}$ Shunqin Zhang, ${ }^{2}$ Liangyi Xue, \\ Qinggang Xue, ${ }^{2}$ and Yongbo $\mathrm{Bao}^{2}$ \\ ${ }^{1}$ School of Marine Sciences, Ningbo University, Ningbo 315211, China \\ ${ }^{2}$ Zhejiang Key Laboratory of Aquatic Germplasm Resources, Zhejiang Wanli University, Ningbo 315100, China \\ Correspondence should be addressed to Qinggang Xue; qxue@zwu.edu.cn and Yongbo Bao; bobbao2001@gmail.com
}

Received 26 October 2016; Accepted 22 December 2016; Published 15 January 2017

Academic Editor: Yang Zhang

Copyright (C) 2017 Sufang Wang et al. This is an open access article distributed under the Creative Commons Attribution License, which permits unrestricted use, distribution, and reproduction in any medium, provided the original work is properly cited.

Hemoglobins are a group of respiratory proteins principally functioning in transport of oxygen and carbon dioxide in red blood cells of all vertebrates and some invertebrates. The blood clam T. granosa is one of the few invertebrates that have hemoglobin-containing red hemocytes. In the present research, the peroxidase activity of T. granosa hemoglobins (Tg-Hbs) was characterized and the associated mechanism of action was deciphered via structural comparison with other known peroxidases. We detected that purified Tg-Hbs catalyzed the oxidation of phenolic compounds in the presence of exogenous $\mathrm{H}_{2} \mathrm{O}_{2}$. Tg-Hbs peroxidase activity reached the maximum at $\mathrm{pH} 5$ and $35^{\circ} \mathrm{C}$ and was inhibited by $\mathrm{Fe}^{2+}, \mathrm{Cu}^{2+}, \mathrm{SDS}$, urea, and sodium azide. Tg- $\mathrm{Hb}$ shared few similarities in amino acid sequence and overall structural characteristics with known peroxidases. However, the predicted structure at their heme pocket was highly similar to that of horseradish peroxidase (HRP) and myeloperoxidase (MPO). This research represented the first systemic characterization of hemoglobin as a peroxidase.

\section{Introduction}

Hemoglobins (Hbs) are iron-containing respiratory proteins existing in red blood cells of all vertebrates and some invertebrates [1]. The principal function of hemoglobins is to transport oxygen and carbon dioxide in the circulation system of animals. Studies have revealed that hemoglobins play roles in host immunity and antioxidant and molting regulation [2]. In addition, there has been evidence showing the presence of "pseudoperoxidase" or peroxidase-like activities in hemoglobins [3-8]. It was proposed that hemoglobins can cause oxidative injuries through production of oxidative radicals $[9,10]$. At the same time, some researchers speculated that hemoglobin peroxidase-like activity may promote oxygen-dependent microbicidal action by catalyzing reactions to produce superoxide ions including some toxic derivatives such as hydroxyl radicals and hypohalous acid [7]. However, these enzyme activities of hemoglobins have been rarely characterized.
The blood clam, T. granosa, is a major fishery and aquacultural bivalve mollusk living on the east coast of China and Southeast Asia. The clam belongs to the family Arcidae, one of a few invertebrate groups that have hemoglobincontaining red hemocytes in the hemolymph. It has been estimated that more than $90 \%$ of total T. granosa hemocyte proteins are hemoglobins [11, 12]. T. granosa hemoglobin (Tg-Hb) exists in two forms: $\mathrm{Tg}-\mathrm{HbI}$ and $\mathrm{Tg}$-HbII. Tg$\mathrm{HbI}$ is a homogenous dimer consisting of identical subunits, whereas $\mathrm{Tg}-\mathrm{HbII}$ is a heterogeneous tetramer formed by two types of subunits that differ from each other and from Tg$\mathrm{HbI}$ subunit in molecular weight and isoelectric point [13]. Research results have shown that Tg-HbI and Tg-HbII both have antibacterial activities [14]. The mechanisms underlying the activities, however, remain to be investigated.

In a previous research, $\mathrm{Tg}$-Hbs have been detected to have peroxidase activity [14]. The objectives of the present research were to determine the enzymatic characteristics of the two $\mathrm{Tg}-\mathrm{Hb}$ in catalyzing oxidative reactions and the 


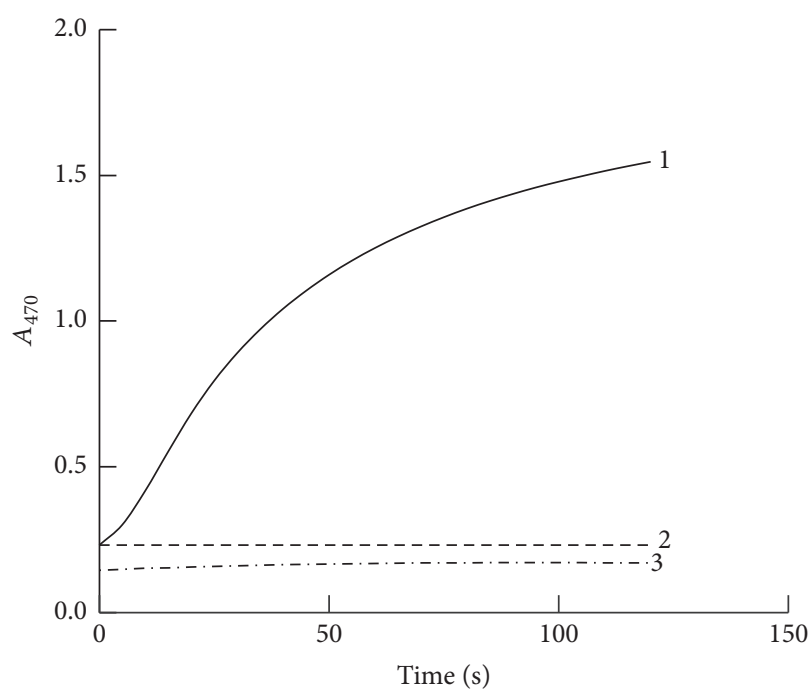

(a)

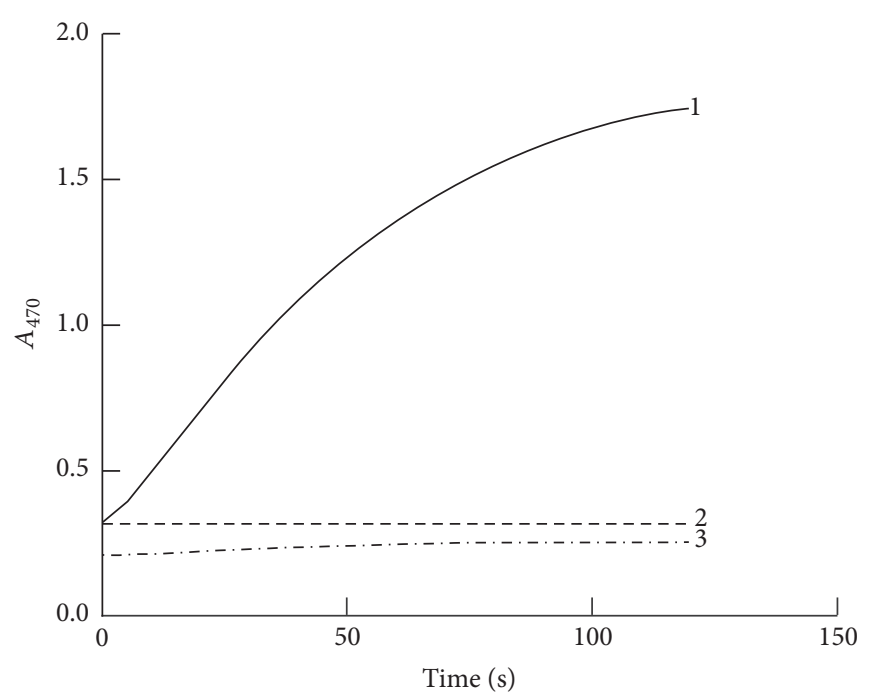

(b)

Figure 1: The peroxidase activity of Tg-Hb. (a) Tg-HbI, (b) Tg-HbII; 1: Tg- $\mathrm{Hb}+$ guaiacol $+\mathrm{H}_{2} \mathrm{O}_{2}, 2: \mathrm{Tg}-\mathrm{Hb}+\mathrm{H}_{2} \mathrm{O}_{2}$, and 3: Tg-Hb + guaiacol.

related mechanism. The results should help in better assessing hemoglobin functions in host defense of bivalve mollusks in the Arcidae family.

\section{Materials and Methods}

2.1. Materials. Tg-Hbs were purified from T. granosa hemocytes as reported previously [15]. Guaiacol (GA), L-dihydroxyphenylalanine (L-DOPA), lipopolysaccharide (LPS), and lipoteichoic acid (LTA) were purchased from Sigma-Aldrich. All other chemicals were products of the highest analytical grade.

2.2. Peroxidase Activity Assay. Peroxidase activity was measured by the method previously described [16] with some modifications. The method is based on the generation of tetraguaiacol from guaiacol by peroxidase in the presence of $\mathrm{H}_{2} \mathrm{O}_{2}$. Measurements were performed by mixing $1 \mathrm{ml}$ of substrate solution containing $4 \mathrm{mM}$ guaiacol, $2 \mathrm{mM} \mathrm{H}_{2} \mathrm{O}_{2}$, and $50 \mathrm{mM}$ sodium phosphate buffer, with $\mathrm{pH} 7.0$ as substrate buffer with $10 \mu \mathrm{l}$ of $\mathrm{Tg}-\mathrm{Hb}$ at $3 \mathrm{mg} / \mathrm{L}$ in substrate buffer. After brief shaking to mix thoroughly, the mixture was measured continuously for $2 \mathrm{~min}$ at room temperature for the absorbance at $470 \mathrm{~nm}$ using a Shimadzu UV-1800 spectrophotometer connected with a recorder. As the reaction consists of the formation of one molecule of tetraguaiacol and 4 molecules of $\mathrm{H}_{2} \mathrm{O}$ from 4 molecules of guaiacol and 2 molecules of $\mathrm{H}_{2} \mathrm{O}_{2}$, the enzyme activity was calculated from $\Delta A_{470} / \mathrm{min}$ according to the following formula: $\varepsilon$ (tetraguaiacol) $)_{470}=26600 \mathrm{M}^{-1} \mathrm{~cm}^{-1}$.

2.3. Peroxidase Property Characterization. The optimal temperature for $\mathrm{Tg}-\mathrm{Hb}$ peroxidase activity was determined by measuring the activities at temperatures between $10^{\circ} \mathrm{C}$ and $60^{\circ} \mathrm{C}$ in the buffer described earlier. The optimal $\mathrm{pH}$ was determined by measuring the activities in citrate or Tris$\mathrm{HCl}$ buffers at different $\mathrm{pH}$ values ranging from $\mathrm{pH} 2$ to $\mathrm{pH} 10$ at $25^{\circ} \mathrm{C}$. Kinetics assays were carried out to determine Michaelis-Menten constants.

To test the effects of SDS, urea, guanidine hydrochloride, lipopolysaccharide (LPS), lipoteichoic acid (LTA), $\mathrm{NaN}_{3}$, and metal ions on $\mathrm{Tg}-\mathrm{Hb}$ peroxidase activity, related materials dissolved in $50 \mathrm{mM}$ acetic acid buffer ( $\mathrm{pH}$ 5.0) at different concentrations were incubated with purified Tg-Hbs for $2 \mathrm{~h}$ at $25^{\circ} \mathrm{C}$, and peroxidase activities were then measured. All measurements were done in triplicate.

2.4. Sequence Based Biochemical Property Prediction and Comparison. The amino acid sequences of $\mathrm{Tg}-\mathrm{Hb}, \mathrm{MPO}$, and HRP were retrieved from the NCBI GenBank (https://www .ncbi.nlm.nih.gov/). Basic biochemical properties of related proteins were predicted by the program ProtParam (http:// web.expasy.org/protparam). Multiple sequence alignments were done using the program Clustal $\mathrm{X}$ and colored using the program ESPript (http://espript.ibcp.fr/ESPript/cgi-bin/ ESPript.cgi).

2.5. Tertiary Structure Prediction and Activity Site Analysis. Three-dimensional structures of Tg-Hbs were modeled using the program SWISS-MODEL (https://swissmodel.expasy .org/) with $\mathrm{HbI}$ (PDB 3g53) and HbII (PDB 4hrr) from Scapharca inaequivalvis as templates. The heme and the related key amino acid residues of the analyzed proteins were displayed with Chimera (version 1.11.2).

\section{Results}

3.1. Peroxidase Activity of $\mathrm{Tg}-\mathrm{Hb}$. The absorbance of reaction tubes containing substrate and either Tg-HbI (Figure 1(a)) or Tg-HbII (Figure 1(b)) increased with incubation time. In contrast, the absorbance of reaction tubes containing $\mathrm{Tg}$-Hbs plus incomplete substrate solutions without either $\mathrm{H}_{2} \mathrm{O}_{2}$ or 


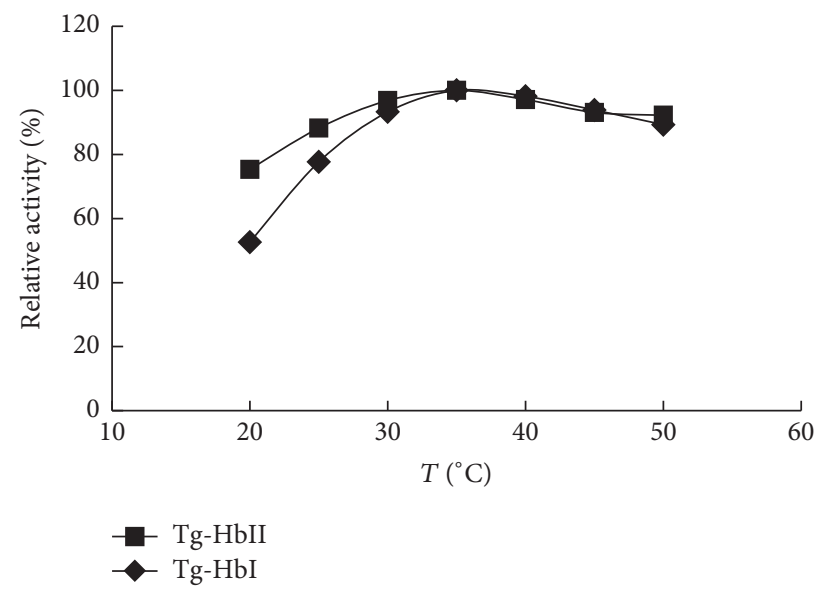

(a)

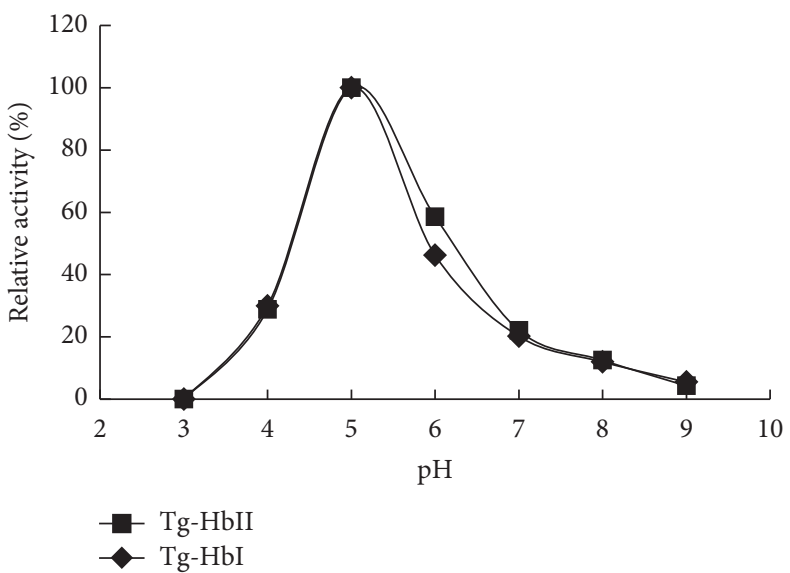

(b)

FIgURE 2: Effect of temperature and $\mathrm{pH}$ on $\mathrm{Tg}-\mathrm{Hb}$ activity.

guaiacol did not change with incubation time (Figures 1(a) and $1(b))$.

3.2. Temperature and $p H$ Optima. The peroxidase activities of purified $\mathrm{Tg}$-Hbs measured at various temperatures and $\mathrm{pH}$ values were shown in Figure 2. The relative peroxidase activity of both $\mathrm{Tg}$-Hbs increased from $20^{\circ} \mathrm{C}$ to $35^{\circ} \mathrm{C}$ and then decreased gradually. At $50^{\circ} \mathrm{C}$, the relative activity retained about $80 \%$ of the maximum (Figure $2(\mathrm{a})$ ). At $\mathrm{pH} \mathrm{3,} \mathrm{the}$ peroxidase activity of $\mathrm{Tg}$-Hbs was not detected. The relative activity then increased to $30 \%$ at $\mathrm{pH} 4$ and reached the maximum at $\mathrm{pH} 5$ and then decreased as $\mathrm{pH}$ increased. At $\mathrm{pH}$, both $\mathrm{Tg}-\mathrm{Hb}$ did not have detectable peroxidase activity (Figure 2(b)).

3.3. Michaelis-Menten Constants and Substrate Specificity. Michaelis-Menten constants of Tg-Hbs catalyzing guaiacol were calculated from the Lineweaver-Burk plot (Figure 3). The calculated constants were $K_{m}^{\mathrm{GA}}=0.15$ and $K_{\mathrm{m}}^{\mathrm{H}_{2} \mathrm{O}_{2}}=0.54$ for Tg-HbI and $K_{\mathrm{m}}^{\mathrm{GA}}=0.39$ and $K_{\mathrm{m}}^{\mathrm{H}_{2} \mathrm{O}_{2}}=0.40$ for Tg$\mathrm{HbII}$. The catalysis of oxidization of catechol, hydroquinone, phenol, and dopamine was also measured and the related Michaelis-Menten constants were shown in Table 1.

3.4. Effects of Chemicals on $\mathrm{Tg}-\mathrm{Hb}$ Peroxidase Activity. The peroxidase activity of Tg-HbI and Tg-HbII decreased with the presence of $\mathrm{Fe}^{2+}$ at incremental concentrations from $1 \mathrm{mM}$ to $8 \mathrm{mM}$. When $8 \mathrm{mM} \mathrm{Fe}{ }^{2+}$ was added in the reaction, only $40 \%$ of the original enzyme activity was retained (Figure 4(a)). The activity also decreased with the addition of $\mathrm{Cu}^{2+}$ in the reaction. Tg-HbI peroxidase activity was almost completely abolished when $\mathrm{Cu}^{2+}$ concentration reached $0.5 \mathrm{mM}$ (Figure $4(\mathrm{~b})$ ). Although $\mathrm{Tg}-\mathrm{HbII}$ peroxidase activity decreased sharply with $\mathrm{Cu}^{2+}$ increase at the low concentration range, it tolerated relatively higher $\mathrm{Cu}^{2+}$ concentrations and retained more than $20 \%$ maximal activity in the presence of $10 \mathrm{mM} \mathrm{Cu}^{2+}$ (Figure 4(c)). Metal ions of $\mathrm{Mn}^{2+}$,
TABLE 1: Michaelis-Menten constants of Tg-Hb.

\begin{tabular}{lcccc}
\hline \multirow{2}{*}{ Phenols } & \multicolumn{2}{c}{ Tg-HbI } & \multicolumn{2}{c}{ Tg-HbII } \\
& $K_{\mathrm{m}}^{\mathrm{p}}$ & $K_{\mathrm{m}}^{\mathrm{H}_{2} \mathrm{O}_{2}}$ & $K_{\mathrm{m}}^{\mathrm{p}}$ & $K_{\mathrm{m}}^{\mathrm{H}_{2} \mathrm{O}_{2}}$ \\
\hline Guaiacol & 0.15 & 0.54 & 0.39 & 0.40 \\
Pyrocatechol & 0.097 & 7.28 & 0.087 & 0.37 \\
L-DOPA & 1.44 & 1.97 & 2.65 & 1.25 \\
Phenol & 1378.55 & 1.07 & 4.49 & 1.81 \\
Hydroquinone & 108.25 & 1.62 & 5.77 & 10.09
\end{tabular}

Note: $K_{\mathrm{m}}^{\mathrm{p}}$ : Michaelis-Menten constants for phenols.

$\mathrm{Mg}^{2+}, \mathrm{Zn}^{2+}$, and $\mathrm{Pb}^{2+}$ were not detected to impact on $\mathrm{Tg}-\mathrm{Hb}$ peroxidase activity.

$\mathrm{Tg}-\mathrm{Hb}$ peroxidase activity decreased drastically with the addition of SDS at increasing concentrations (Figure 4(d)). The activity retained $20 \%$ of the maximum and almost completely lost with presence of SDS at $1.5 \mathrm{mM}$ and $8 \mathrm{mM}$, respectively. The peroxidase activity of both $\mathrm{Tg}$-Hbs was retained at urea concentration up to $2 \mathrm{M}$ and decreased with the elevation of urea concentration. When urea concentration reached $6 \mathrm{M}$, no peroxidase activity was detected in both proteins (Figure 4(e)).

$\mathrm{Tg}-\mathrm{Hb}$ peroxidase activity was also inhibited by $\mathrm{NaN}_{3}$ in a dose-dependent manner (Figure 4(f)). The activity decreased by $50 \%$ and $80 \%$ when $\mathrm{NaN}_{3}$ was added to $1 \mathrm{mM}$ and $5 \mathrm{mM}$, respectively.

3.5. Effects of LPS and LTA on Tg-Hb Peroxidase Activity. LPS and LTA at the concentration of $100 \mu \mathrm{g} / \mathrm{ml} \mathrm{did}$ not show effects on the peroxidase activity of the two Tg-Hbs (Figure 5).

3.6. Biochemical Comparison between $\mathrm{Tg}$-Hbs and the Representative Peroxidases. The predicted biochemical characteristics of the three types of subunit (Tg-Hbi that forms the 


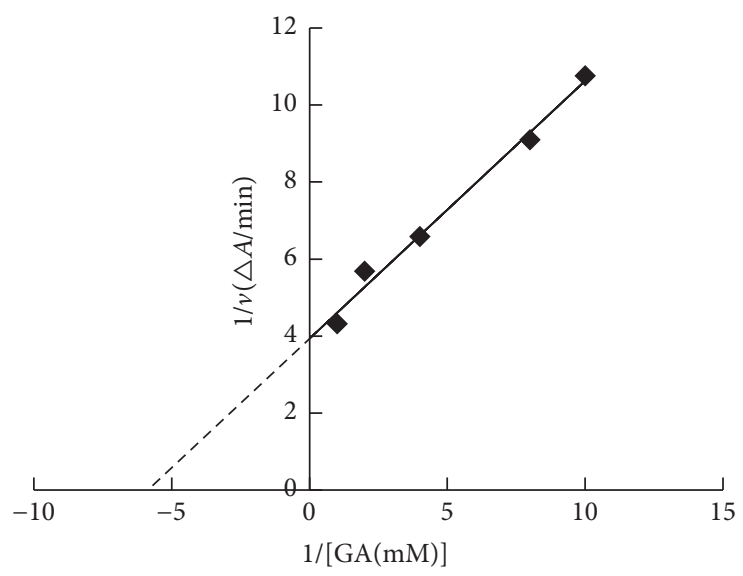

(a)

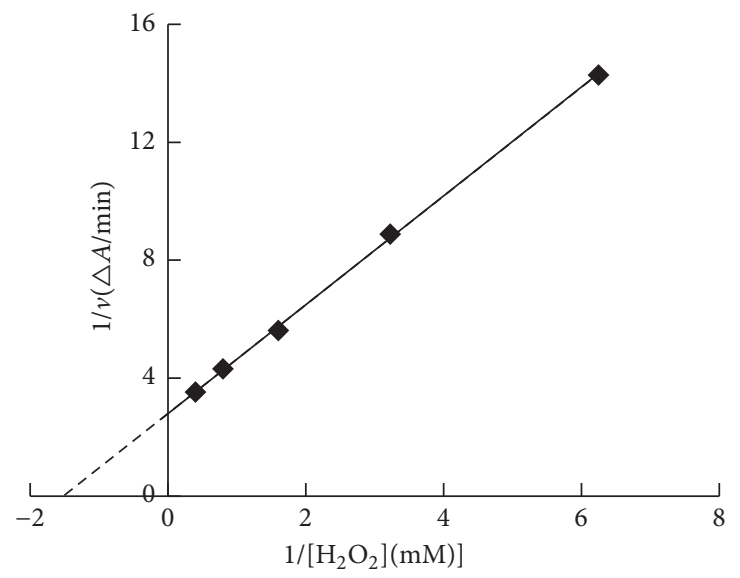

(c)

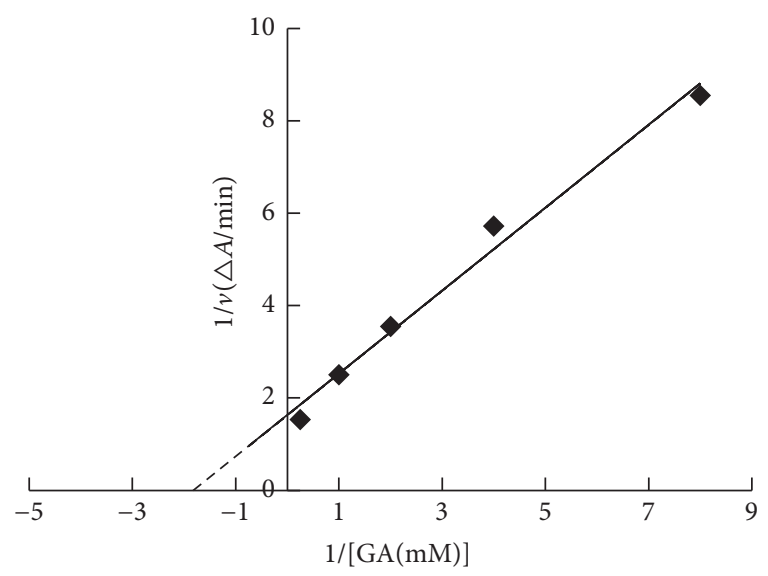

(b)

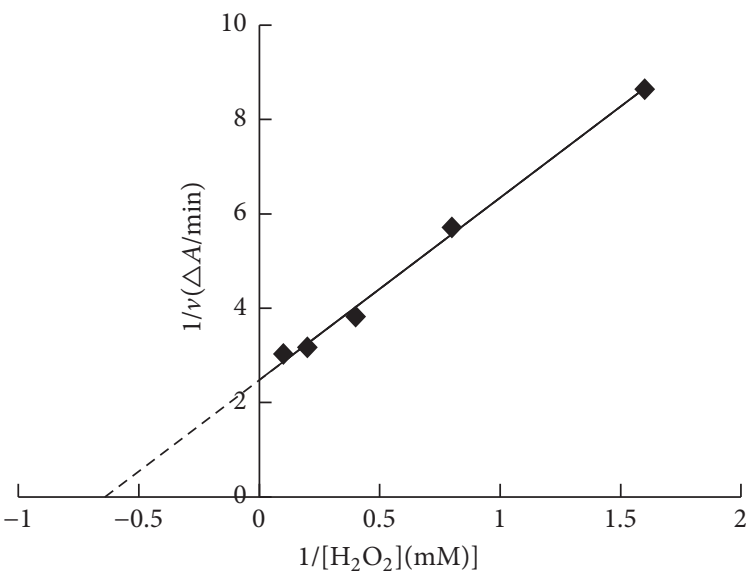

(d)

Figure 3: Lineweaver-Burk plot for the Michaelis-Menten constant. (a, c) Tg-HbI; (b, d) Tg-HbII.

dimer Tg-HbI and Tg-Hbii $\alpha$ and Tg-Hbii $\beta$ that form the tetramer Tg-HbII) were compared with those of horse radish peroxidase (HRP), a representative of plant peroxidase, and myeloperoxidase (MPO), a representative peroxidase of vertebrates. As shown in Table 2, the subunits differed from each other in molecular weight, isoelectric point (pI), cysteine residues number, and total amino acids number.

3.7. Sequence Comparison between $\mathrm{Tg}$-Hb Subunits and Representative Peroxidases. The amino acid sequence of the three $\mathrm{Tg}-\mathrm{Hb}$ subunits was aligned with that of HRP and the MPO heavy chain (Figure 6). The similarity between these polypeptides at the primary structural level was low. The MPO light chain was not included in the alignment because it does not contain heme and the overall sequence similarity is even lower.

3.8. Predicted Protein and Heme Pocket Structures. Sequence alignment indicated that $\mathrm{Tg}$-Hbi shared $81.51 \%$ sequence identity with the $\mathrm{S}$. inaequivalvis hemoglobin $(\mathrm{Si}-\mathrm{Hb})$ subunit $3 g 53$ in the PDB, and Tg-Hbii $\alpha$ and Tg-Hbii $\beta$ shared 91.23\% and $36.7 \%$ sequence identity, respectively, with the $\mathrm{Si}-\mathrm{Hb}$ subunit $4 \mathrm{hrr}$ in the PDB. The 3D structures of the three
Tg-Hb subunits were modeled using the SWISS-MODEL program with $\mathrm{Si}-\mathrm{Hb}$ subunits as templates. $\mathrm{Tg}-\mathrm{Hb}$ subunits shared similarities with related $\mathrm{Si}-\mathrm{Hb}$ subunits in secondary structural elements including $\alpha$-helices, random coil, and $\beta$ sheets and tertiary structure. The predicted heme pocket of $\mathrm{Tg}-\mathrm{Hb}$ subunits was particularly similar to that of $\mathrm{Si}-\mathrm{Hb}$ in amino acid sequence and tertiary structure. Therefore, the heme structure and key residues in the pocket of the Si$\mathrm{Hb}$ subunits were compared with those of HRP and MPO (Figure 7). All the compared structures contained a type b heme, of which the substrate oxidation site was formed by a region that included the heme methyl $\mathrm{C} 18$ and meso protons of heme C20. In addition, the positions of the proximal His and distal His and the Arg residues that are key to the functionality of the heme pocket were also conserved (Figure 7). Tg-Hb subunits show little similarity with HRP and MPO at the tertiary level.

\section{Discussion}

Hemoglobins represent a group of oxygen transport proteins present in red blood cells of all vertebrates and the red hemocytes of some invertebrates. There are increasing research 


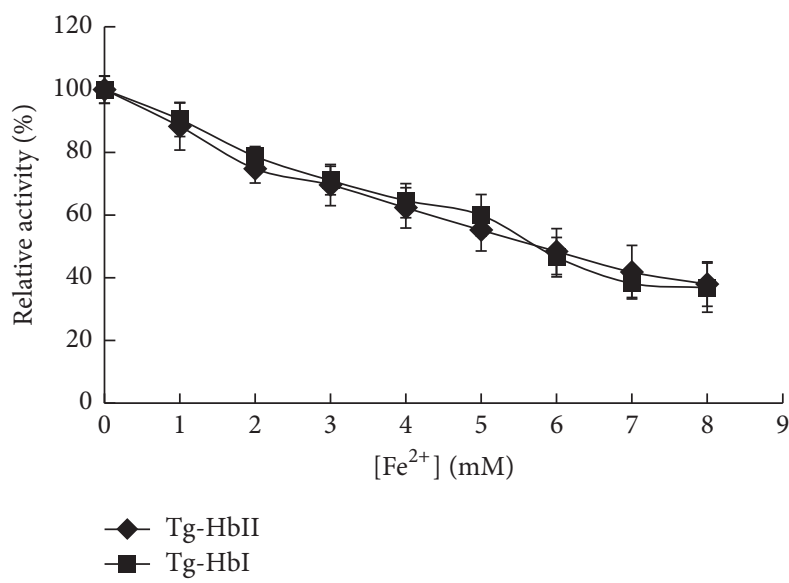

(a)

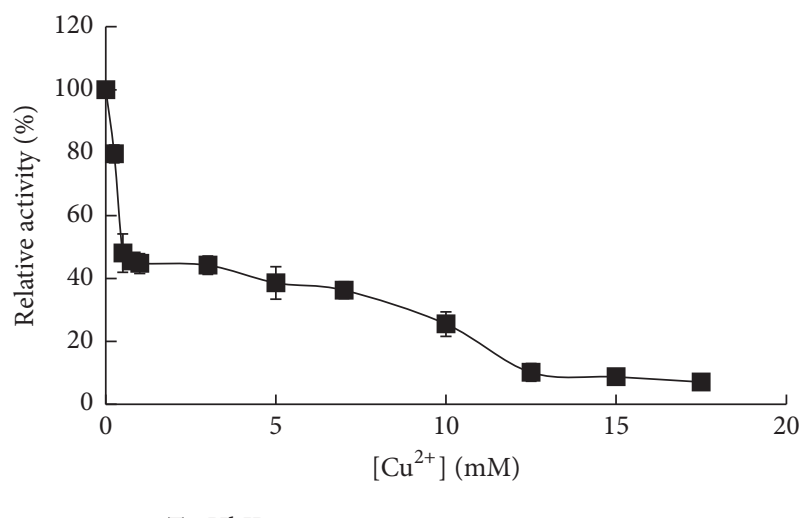

Tg-HbII

(c)

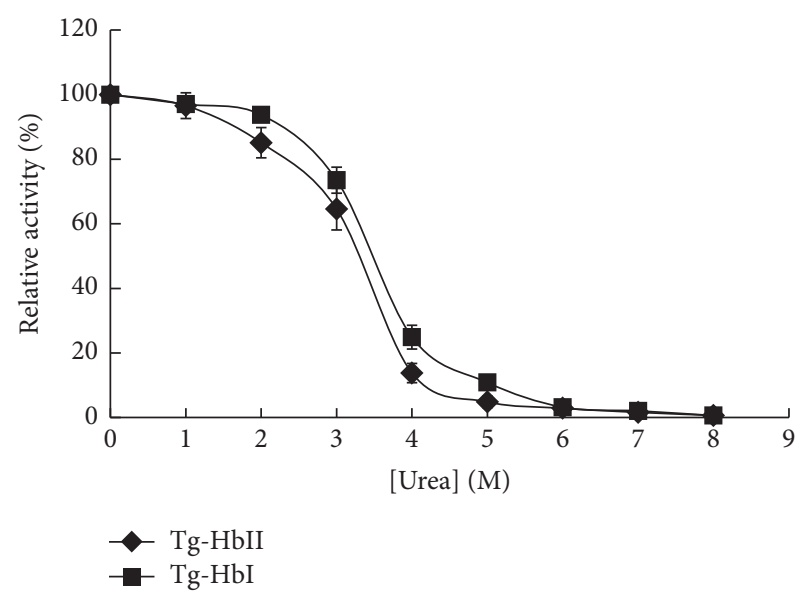

(e)

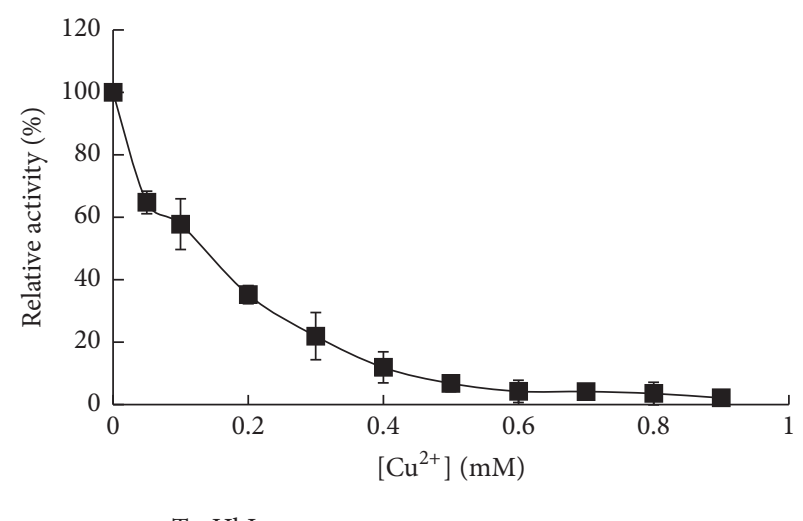

(b)

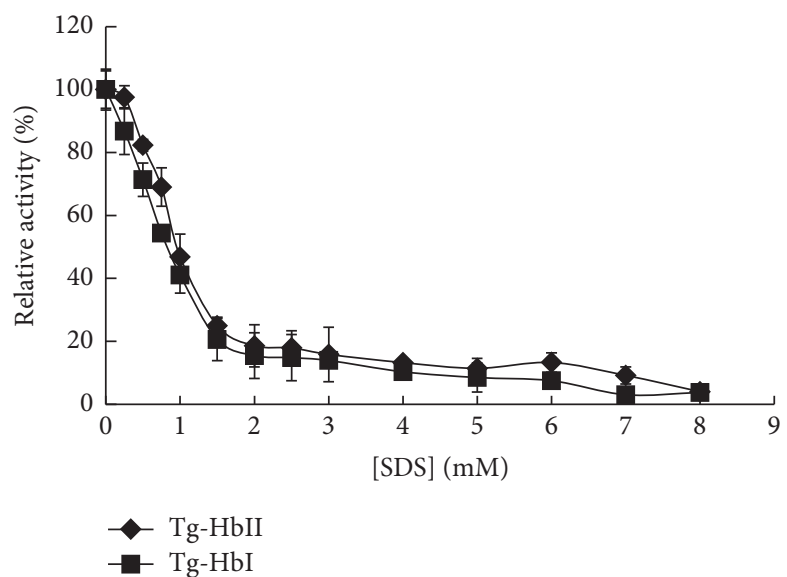

(d)

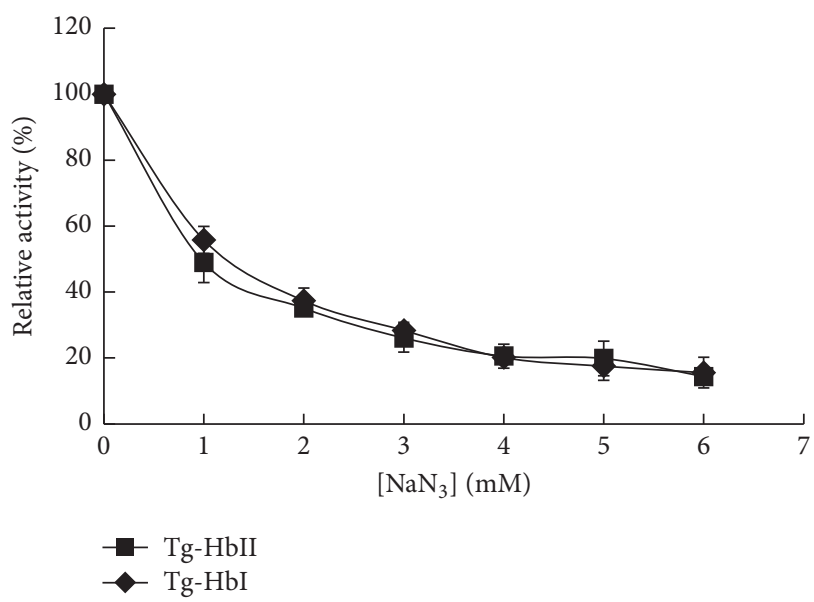

(f)

FIgURE 4: The effect of chemicals on Tg-Hb peroxidase activity.

results that suggest immune functions of these proteins. The blood clam T. granosa is one of the few invertebrates that have hemoglobins. Tg-Hbs have been studied for the potential function in host immunity. Findings in the present research indicated that $\mathrm{Tg}-\mathrm{Hb}$ may function as peroxidase in the clam's hemocytes.
Purified Tg-Hbs catalyzed the oxidation of several phenol compounds in the presence of $\mathrm{H}_{2} \mathrm{O}_{2}$, with high affinity to guaiacol and $\mathrm{H}_{2} \mathrm{O}_{2}$ as indicated by the related $\mathrm{Km}$ values. Spectrophotometrically monitoring the conversion of the colorless guaiacol to the dark brown tetraguaiacol is a standard technique to measure peroxidase activity [17]. 


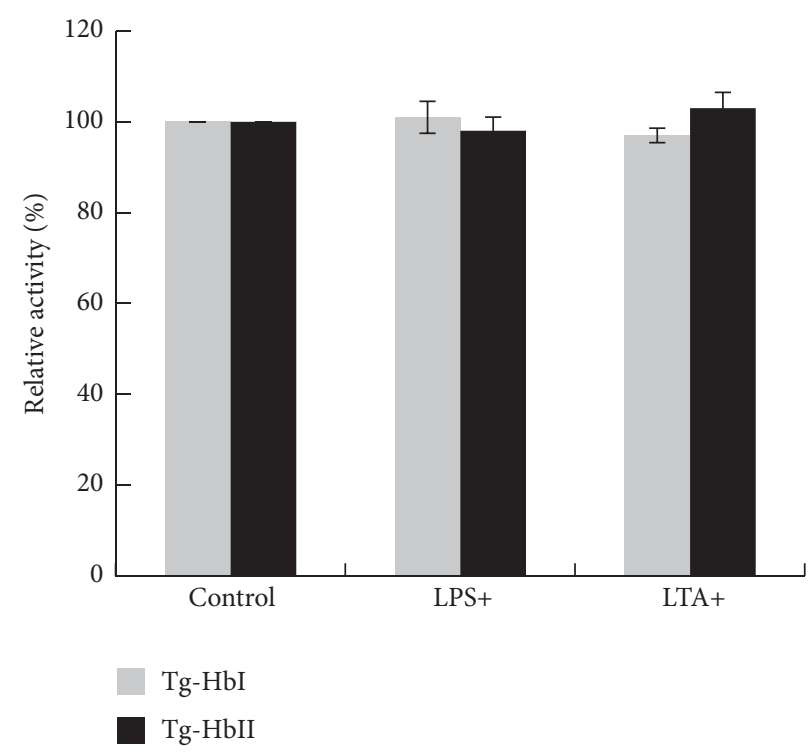

FIGURE 5: The effect of LPS and LTA on Tg-Hb peroxidase activity.

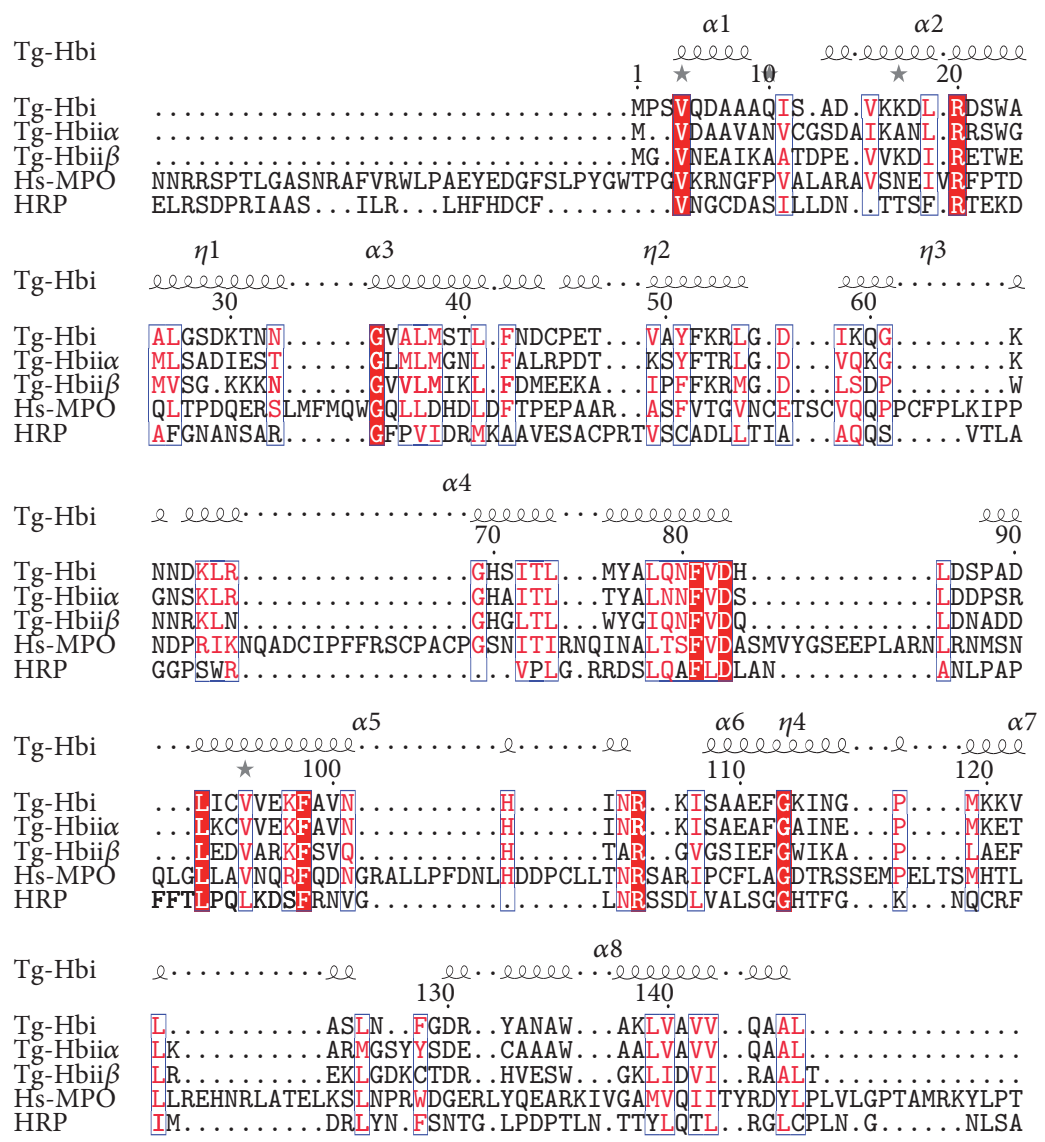

FIGURE 6: Amino acid sequence alignment of four proteins. Same amino acid residues are shaded in red, similar amino acids are shaded in box, and $\alpha$-helices are shown as $\alpha 1$ to $\alpha 8$. 
TABLE 2: Basic biochemical properties of Tg-Hb, MPO, and HRP.

\begin{tabular}{lcccccc}
\hline Peptides & Accession & Species & Molecular weight & pI & Cys & Amino acids number \\
\hline Tg-Hbi & HQ149305 & T. granosa & 16037.4 & 8.89 & 2 & 147 \\
Tg-Hbii $\alpha$ & HQ729976 & T. granosa & 16231.7 & 8.81 & 3 & 150 \\
Tg-Hbii $\beta$ & HQ149306 & T. granosa & 17232.7 & 5.66 & 1 & 152 \\
HRP & 1KZM_A & Armoracia rusticana & 33841.1 & 5.47 & 6 & 308 \\
MPO H & 1MHL_C & Homo sapiens & 53164.5 & 9.48 & 12 & 466 \\
MPO L & 1MHL_A & Homo sapiens & 12318.9 & 5.77 & 2 & 108 \\
\hline
\end{tabular}

Note: Tg-Hbi: Tg-HbI subunit; Tg-Hbii $\alpha$ : Tg-HbII subunit $\alpha$; Tg-Hbii $\beta$ : Tg-HbII subunit $\beta$; MPO H: MPO heavy chain; MPO L: MPO light chain.

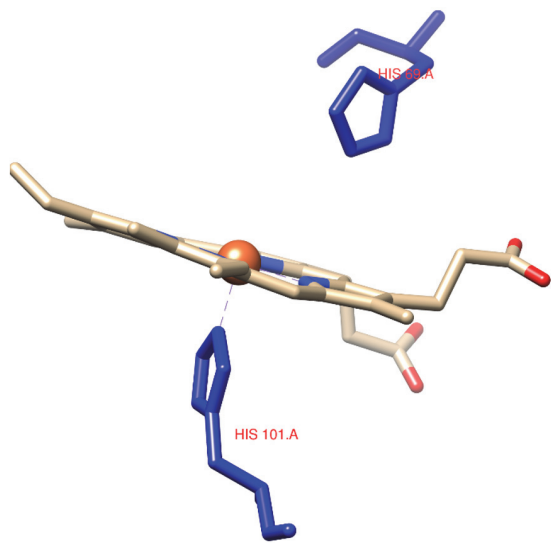

(a)

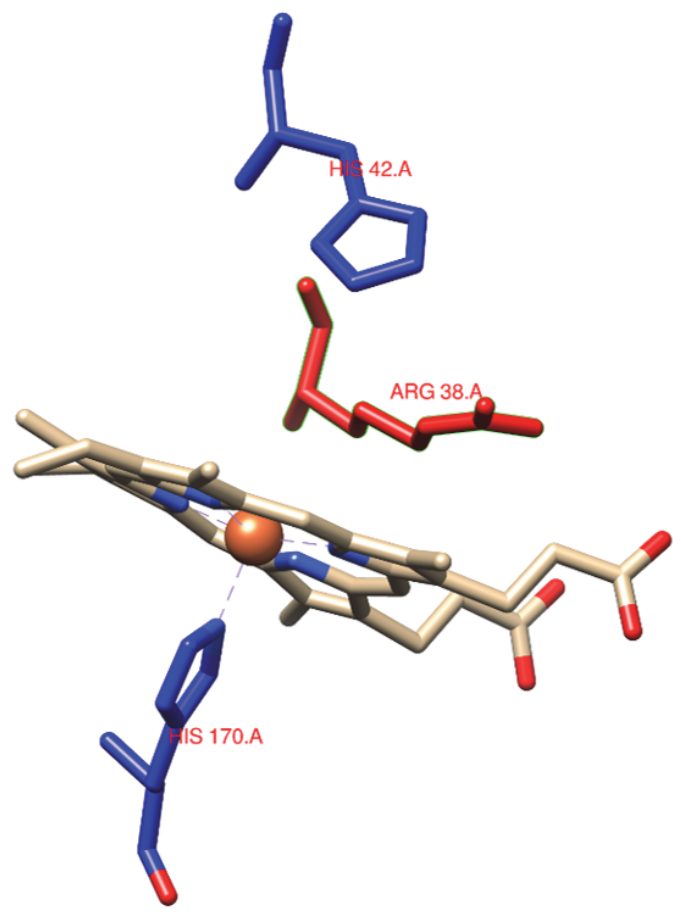

(c)

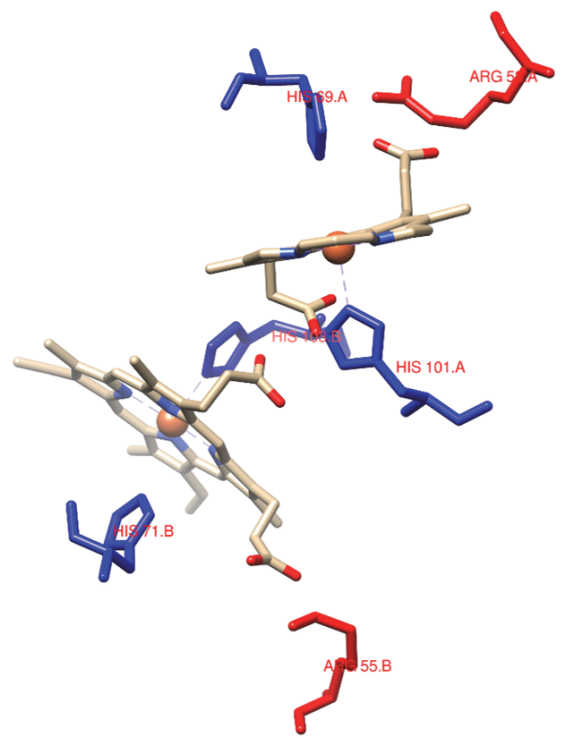

(b)

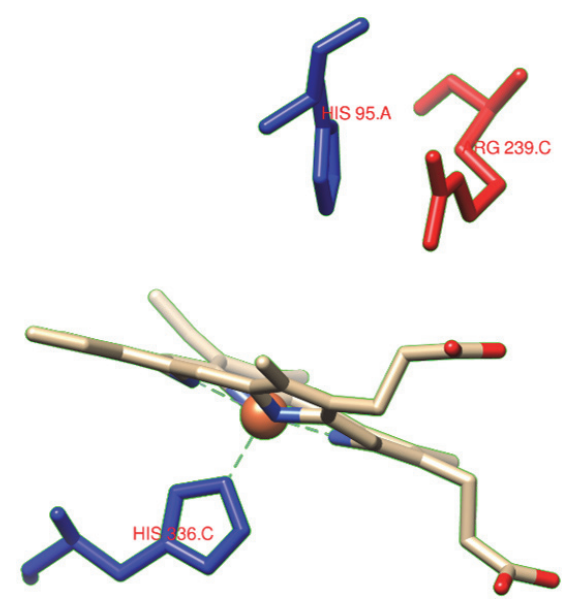

(d)

Figure 7: The heme and near key residues of Si-Hb I (a), Si-Hb II (b), HRP (c), and MPO (d). 
Although phenoloxidases also catalyze phenol oxidation, the catalysis does not require exogenous $\mathrm{H}_{2} \mathrm{O}_{2}$ [18]. In the present research, the oxidation activity of purified $\mathrm{Tg}-\mathrm{Hbs}$ was not detected when $\mathrm{H}_{2} \mathrm{O}_{2}$ was absent in the reactions. In addition, $\mathrm{Tg}$-Hbs showed maximal peroxidase activity at $\mathrm{pH}$ 5.0 and the activity was inhibited by $\mathrm{NaN}_{3}$. These enzymatic characteristics conformed to those of HRP and MPO [19]. Therefore, $\mathrm{Tg}$-Hbs possibly possess peroxidase activity.

Several factors affected the peroxidase activity of TgHbs. In addition to temperature, $\mathrm{pH}$, and $\mathrm{NaN}_{3}$, some metal ions and protein denaturants affected the activity. A possible reason for $\mathrm{Fe}^{2+}$ inhibiting $\mathrm{Tg}-\mathrm{Hb}$ peroxidase activity is the consumption of $\mathrm{H}_{2} \mathrm{O}_{2}$ by the oxidization of the ferrous ions as $\mathrm{H}_{2} \mathrm{O}_{2}$ is essential for the peroxidase catalysis. Differences in sensitivity and response pattern to $\mathrm{Cu}^{2+}$ were observed between $\mathrm{Tg}$-HbI and $\mathrm{Tg}$-HbII which suggested that a more complex mechanism was likely involved in the response of Tg-Hbs to the metal ion. For the protein denaturants, SDS disrupts hydrophobic interactions in protein molecules, while urea interacts with amide groups and peptides to destabilize protein structures [20]. These interactions can change the conformations of Tg-Hbs, in particular the active center (i.e., the heme pocket), resulting in the loss of peroxidase activity. It has been reported that sodium azide is a proven inhibitor of peroxidases including MPO and HRP, and the inactivation involves the binding of sodium azide to the heme, thus preventing substrates from oxidization $[20,21]$.

It is worth noting that the two $\mathrm{Tg}$-Hbs showed some differences in peroxidase activities. For example, they have different $\mathrm{Km}$ values for the tested substrates, suggesting differences in substrate specificities. They also significantly differed in tolerating the inhibition by $\mathrm{Cu}^{2+}$. In addition, $\mathrm{Tg}$ $\mathrm{HbI}$ and $\mathrm{Tg}$-HbII are different in subunit types and subunit number [14]. Future studies should be done to assess whether the differences in enzymatic properties are determined at the subunit level or at the quaternary structure level.

HRP and MPO are hemoproteins and both have a hydrophobic heme pocket that contains a type b pentacoordinated heme with proximal His and distal His, being critical for the peroxidase activity. The open site of the heme can bind oxygen $\left(\mathrm{O}_{2}\right)$, nitric oxide $(\mathrm{NO})$, carbon monoxide (CO), or $\mathrm{H}_{2} \mathrm{O}_{2}[19,22]$. When bound to the heme, $\mathrm{H}_{2} \mathrm{O}_{2}$ oxidizes the $\mathrm{Fe}$ (III) state heme to generate a higher oxidative state intermediate comprising Fe (IV) oxoferryl center and a porphyrin-based cation radical [23]. The oxidative intermediate then gives rise to adducts such as C18-hydroxymethyl and C20-meso-phenyl heme derivatives, which can further oxidize the bound substrate [24]. The distal His residue functions as a receptor of the $\mathrm{H}_{2} \mathrm{O}_{2}$ proton and to bind and stabilize ligands and aromatic substrates together with the Arg residue in the heme pocket $[22,24,25]$. Our results in comparison of the heme pocket suggested that the structural elements essential for the peroxidase activity are highly similar between $\mathrm{Si}-\mathrm{Hb}$ and the two known peroxidases. As the $\mathrm{Tg}-\mathrm{Hb}$ heme pocket is identical to the $\mathrm{Si}-\mathrm{Hb}$ heme pocket, it is reasonable to predict that the mechanism of action underlying the detected $\mathrm{Tg}-\mathrm{Hb}$ peroxidase activity should be the same as the other known peroxidases.
$\mathrm{Xu}$ et al. reported that the Scapharca kagoshimensis hemoglobins have phenoloxidase activity [26]. We did not detect any catalysis activity in purified Tg-Hbs when measured without $\mathrm{H}_{2} \mathrm{O}_{2}$; thus the phenoloxidase activity could not be confirmed in the T. granosa hemoglobins. It should be mentioned that, unlike hemoglobin and other hemoproteins, hemocyanin and phenoloxidase have copper as prosthetic for their enzyme activity. In addition, studies on hemocyanin have revealed that treatments with SDS, proteolytic enzymes, PAMPS, and pathogen invasion can convert the invertebrate oxygen transport protein to have phenoloxidase activity [2730]. Jiang et al., for example, reported that LPS, LTA, and bacteria proteinase could activate the phenoloxidase activity of hemocyanin [7]. However, LPS and LTA did not show any effects on Tg-Hb enzyme activity in the present study. Further research is needed to draw the conclusion whether $\mathrm{Tg}-\mathrm{Hbs}$ have other enzyme activities.

There is evidence for the involvement of peroxidases in host defense [31-34]. For example, MPO and lactoperoxidase (LPO) have been well studied for their antibacterial activity [35-37]. It has been reported that MPO plays an important role in the microbicidal activity of phagocytes. When neutrophils engulf pathogens, they also produce $\mathrm{H}_{2} \mathrm{O}_{2}$ along with the respiratory burst. With the presence of $\mathrm{H}_{2} \mathrm{O}_{2}$, MPO oxidizes halide (particularly chloride) ion to form highly reactive halide-derived oxidants [37-39]. T. granosa red hemocytes appeared to phagocytose particles [40]. Given the hemoglobin's extreme abundance in red hemocytes, it is plausible to speculate that $\mathrm{Tg}-\mathrm{Hb}$ may function in the phagocytosis of the clam hemocytes in the same way as MPO in neutrophils. Studies observing peroxidase activity change in hemocytes during pathogen phagocytosis should provide further information about the function of $\mathrm{Tg}-\mathrm{Hbs}$ in T. granosa host immunity.

\section{Competing Interests}

The authors declare that there are no competing interests regarding the publication of this paper.

\section{Acknowledgments}

This project was supported by National Science Foundation of China (31672678), the Natural Science Foundation of Zhejiang province (LQ15C190001), Natural Science Foundation of Ningbo (2015A610258), Zhejiang Provincial Top Key Discipline of Fisheries, and Zhejiang Provincial Top Key Discipline of Bioengineering. The authors thank Ms. Aixiang Ye for assistance in English editing.

\section{References}

[1] R. Hardison, "Hemoglobins from bacteria to man: evolution of different patterns of gene expression," The Journal of Experimental Biology, vol. 201, no. 8, pp. 1099-1117, 1998.

[2] M. L. Coates, "Hemoglobin function in the vertebrates: an evolutionary model," Journal of Molecular Evolution, vol. 6, no. 4, pp. 285-307, 1975.

[3] T. Kawano, R. Pinontoan, H. Hosoya, and S. Muto, "Monoamine-dependent production of reactive oxygen species 
catalyzed by pseudoperoxidase activity of human hemoglobin," Bioscience, Biotechnology and Biochemistry, vol. 66, no. 6, pp. 1224-1232, 2002.

[4] C. E. Cooper, R. Silaghi-Dumitrescu, M. Rukengwa, A. I. Alayash, and P. W. Buehler, "Peroxidase activity of hemoglobin towards ascorbate and urate: a synergistic protective strategy against toxicity of Hemoglobin-Based Oxygen Carriers (HBOC)," Biochimica et Biophysica Acta (BBA)_Proteins and Proteomics, vol. 1784, no. 10, pp. 1415-1420, 2008.

[5] D. M. Minning, A. J. Gow, J. Bonavetura et al., "Ascaris haemoglobin is a nitric oxide-activated 'deoxygenase," Nature, vol. 401, no. 6752, pp. 497-502, 1999.

[6] A. I. Alayash, "Hemoglobin-based blood substitutes: oxygen carriers, pressor agents, or oxidants?" Nature Biotechnology, vol. 17, no. 6, pp. 545-549, 1999.

[7] N. Jiang, N. S. Tan, B. Ho, and J. L. Ding, "Respiratory proteingenerated reactive oxygen species as an antimicrobial strategy," Nature Immunology, vol. 8, no. 10, pp. 1114-1122, 2007.

[8] M. Kvist, E. S. Ryabova, E. Nordlander, and L. Bülow, "An investigation of the peroxidase activity of Vitreoscilla hemoglobin," Journal of Biological Inorganic Chemistry, vol. 12, no. 3, pp. 324334, 2007.

[9] M. Katsu, K. Niizuma, H. Yoshioka, N. Okami, H. Sakata, and P. H. Chan, "Hemoglobin-induced oxidative stress contributes to matrix metalloproteinase activation and blood-brain barrier dysfunction in vivo," Journal of Cerebral Blood Flow and Metabolism, vol. 30, no. 12, pp. 1939-1950, 2010.

[10] T.-M. Cheng, S. J. T. Mao, S.-T. Lai et al., "Haemoglobin-induced oxidative stress is associated with both endogenous peroxidase activity and $\mathrm{H} 2 \mathrm{O} 2$ generation from polyunsaturated fatty acids," Free Radical Research, vol. 45, no. 3, pp. 303-316, 2011.

[11] Y. Bao, Q. Wang, and Z. Lin, "Hemoglobin of the bloody clam Tegillarca granosa (Tg-HbI) is involved in the immune response against bacterial infection," Fish and Shellfish Immunology, vol. 31, no. 4, pp. 517-523, 2011.

[12] Y. Bao, Q. Wang, H. Liu, and Z. Lin, "A small HSP gene of bloody clam (Tegillarca granosa) involved in the immune response against Vibrio parahaemolyticus and lipopolysaccharide," Fish and Shellfish Immunology, vol. 30, no. 2, pp. 729-733, 2011.

[13] Y. B. Bao, Q. Wang, X. M. Guo, and Z. H. Lin, "Structure and immune expression analysis of hemoglobin genes from the blood clam Tegillarca granosa," Genetics and Molecular Research, vol. 12, no. 3, pp. 3110-3123, 2013.

[14] S. Wang, Y. Bao, M. Shi et al., "Purification and antibacterial activity of hemoglobin from Tegillarca granosa," Acta Oceanologica Sinica, vol. 36, no. 12, pp. 67-73, 2014 (Chinese).

[15] Y. Bao, J. Wang, C. Li, P. Li, S. Wang, and Z. Lin, "A preliminary study on the antibacterial mechanism of Tegillarca granosa hemoglobin by derived peptides and peroxidase activity," Fish \& Shellfish Immunology, vol. 51, pp. 9-16, 2016.

[16] H. Woude, Mechanisms of Toxic Action of the Flavonoid Quercetin and Its Phase II Metabolites, Ponsen \& Looijen, 2006.

[17] J.-L. Primus, M. G. Boersma, D. Mandon et al., "The effect of iron to manganese substitution on microperoxidase 8 catalysed peroxidase and cytochrome P450 type of catalysis," Journal of Biological Inorganic Chemistry, vol. 4, no. 3, pp. 274-283, 1999.

[18] B. Hendel, R. L. Sinsabaugh, and J. Marxsen, "Lignin-degrading enzymes: phenoloxidase and peroxidase," in Methods to Study Litter Decomposition, pp. 273-277, Springer Netherlands, 2005.

[19] A. Mika, F. Buck, and S. Lüthje, "Membrane-bound class III peroxidases: identification, biochemical properties and sequence analysis of isoenzymes purified from maize (Zea mays L.) roots," Journal of Proteomics, vol. 71, no. 4, pp. 412-424, 2008.

[20] S.-F. Wang, Y.-X. Si, Z.-J. Wang, S.-J. Yin, J.-M. Yang, and G.-Y. Qian, "Folding studies on muscle type of creatine kinase from Pelodiscus sinensis," International Journal of Biological Macromolecules, vol. 50, no. 4, pp. 981-990, 2012.

[21] P. R. Ortiz De Montellano, "Catalytic sites of hemoprotein peroxidases," Annual Review of Pharmacology and Toxicology, vol. 32, no. 1, pp. 89-107, 1992.

[22] Z.-H. Wang, Y.-W. Lin, F. I. Rosell et al., "Converting cytochrome $\mathrm{c}$ into a peroxidase-like metalloenzyme by molecular design," ChemBioChem, vol. 8, no. 6, pp. 607-609, 2007.

[23] M. Filizola and G. H. Loew, "Role of protein environment in horseradish peroxidase compound I formation: molecular dynamics simulations of horseradish peroxidase- $\mathrm{HOOH}$ complex," Journal of the American Chemical Society, vol. 122, no. 1, pp. 18-25, 2000.

[24] N. C. Veitch, "Horseradish peroxidase: a modern view of a classic enzyme," Phytochemistry, vol. 65, no. 3, pp. 249-259, 2004.

[25] G. I. Berglund, G. H. Carlsson, A. T. Smith, H. Szöke, A. Henriksen, and J. Hajdu, "The catalytic pathway of horseradish peroxidase at high resolution," Nature, vol. 417, no. 6887, pp. 463-468, 2002.

[26] B. Xu, J. Zhao, Z. Jing, Y. Zhang, Y. Shi, and T. Fan, "Role of hemoglobin from blood clam Scapharca kagoshimensis beyond oxygen transport," Fish and Shellfish Immunology, vol. 44, no. 1, pp. 248-256, 2015.

[27] K. Adachi, T. Hirata, T. Nishioka, and M. Sakaguchi, "Hemocyte components in crustaceans convert hemocyanin into a phenoloxidase-like enzyme," Comparative Biochemistry and Physiology Part B: Biochemistry and Molecular Biology, vol. 134, no. 1, pp. 135-141, 2003.

[28] H. Decker and E. Jaenicke, "Recent findings on phenoloxidase activity and antimicrobial activity of hemocyanins," Developmental \& Comparative Immunology, vol. 28, no. 7-8, pp. 673687, 2004.

[29] T. Fan, Y. Zhang, L. Yang et al., "Identification and characterization of a hemocyanin-derived phenoloxidase from the crab Charybdis japonica," Comparative Biochemistry and Physiology-B Biochemistry and Molecular Biology, vol. 152, no. 2, pp. 144-149, 2009.

[30] N. I. Siddiqui, G. Préaux, and C. Gielens, "Intrinsic and induced o-diphenoloxidase activity of $\beta$-hemocyanin of Helix pomatia," Micron, vol. 35, no. 1-2, pp. 91-92, 2004.

[31] A. Daudi, Z. Cheng, J. A. O’Brien et al., “The apoplastic oxidative burst peroxidase in Arabidopsis is a major component of pattern-triggered immunity," Plant Cell, vol. 24, no. 1, pp. 275287, 2012.

[32] L. Almagro, L. V. Gómez Ros, S. Belchi-Navarro, R. Bru, A. Ros Barceló, and M. A. Pedreño, "Class III peroxidases in plant defence reactions," Journal of Experimental Botany, vol. 60, no. 2, pp. 377-390, 2009.

[33] V. Borelli, F. Vita, S. Shankar et al., "Human eosinophil peroxidase induces surface alteration, killing, and lysis of Mycobacterium tuberculosis," Infection and Immunity, vol. 71, no. 2, pp. 605-613, 2003.

[34] E. L. Thomas and T. M. Aune, "Cofactor role of iodide in peroxidase antimicrobial action against Escherichia coli," Antimicrobial Agents and Chemotherapy, vol. 13, no. 6, pp. 1000-1005, 1978. 
[35] J. N. de Wit and A. C. M. Van Hooydonk, "Structure, functions and applications of lactoperoxidase in natural antimicrobial systems," Netherlands Milk and Dairy Journal, vol. 50, pp. 227244, 1996.

[36] H. B. Dunford, "Peroxidase-catalyzed halide ion oxidation," Redox Report, vol. 5, no. 4, pp. 169-171, 2000.

[37] G. Wojciechowski, L. Huang, and P. R. Ortiz De Montellano, "Autocatalytic modification of the prosthetic heme of horseradish but not lactoperoxidase by thiocyanate oxidation products. A role for heme-protein covalent cross-linking," Journal of the American Chemical Society, vol. 127, no. 45, pp. 15871-15879, 2005.

[38] S. J. Klebanoff, "Myeloperoxidase: friend and foe," Journal of Leukocyte Biology, vol. 77, no. 5, pp. 598-625, 2005.

[39] E. Malle, P. G. Furtmüller, W. Sattler, and C. Obinger, "Myeloperoxidase: a target for new drug development?" British Journal of Pharmacology, vol. 152, no. 6, pp. 838-854, 2007.

[40] Z. Zhu, L. Xu, and Z. Zhang, "structural characteristics and phagocytic and enzymatic activities of haemocytes in blood clam Tegillarca granosa," Journal of Fisheries of China, vol. 10, pp. 1494-1502, 2011. 


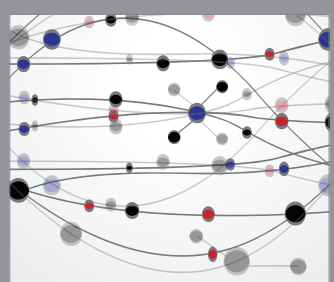

The Scientific World Journal
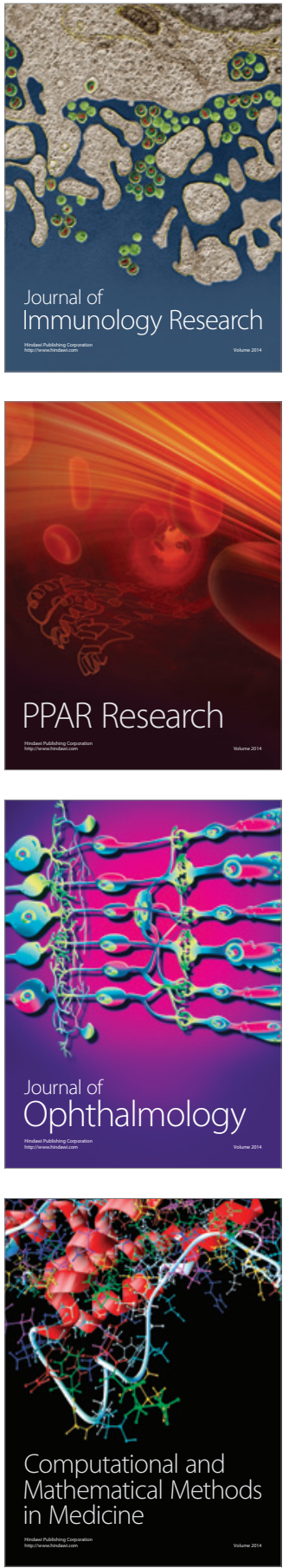

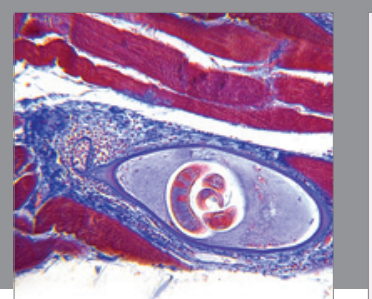

Gastroenterology Research and Practice
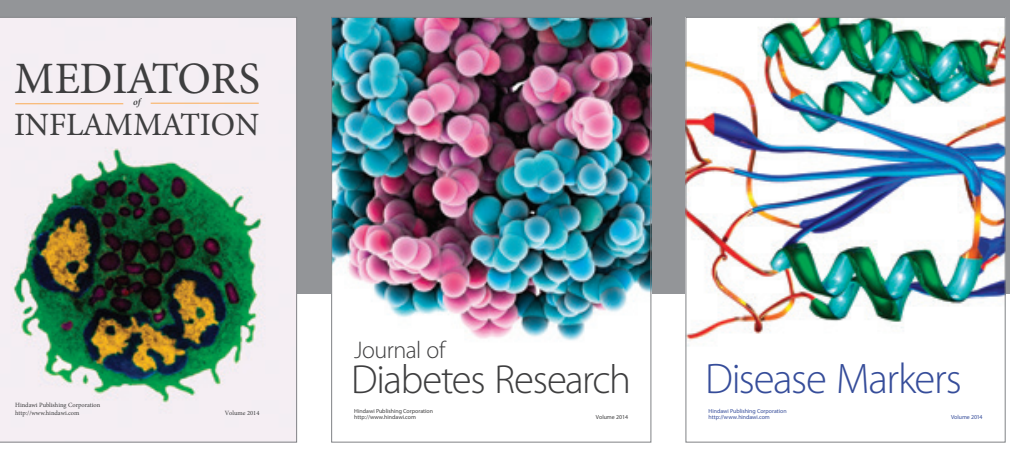

Disease Markers

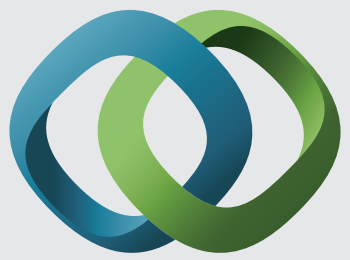

\section{Hindawi}

Submit your manuscripts at

https://www.hindawi.com
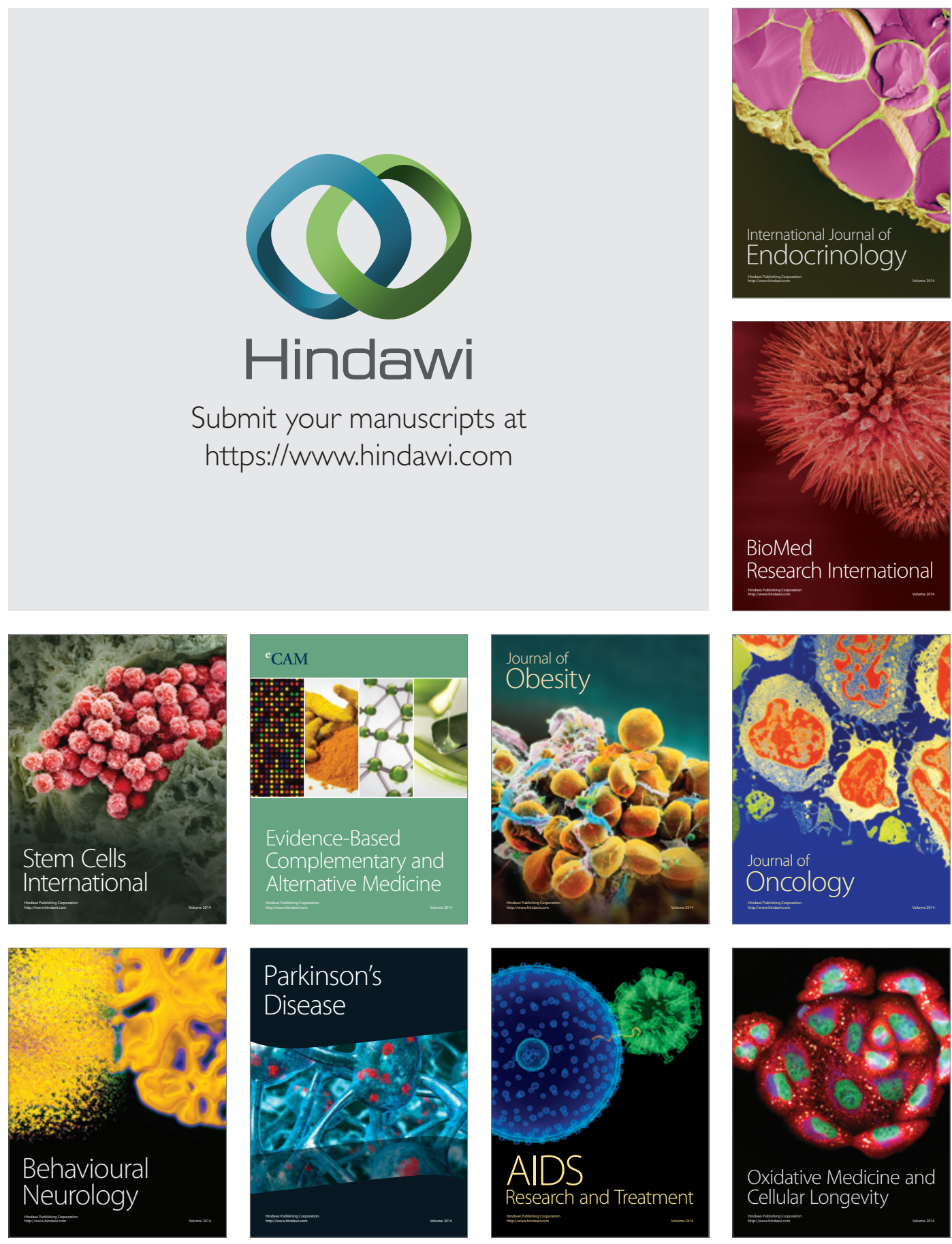